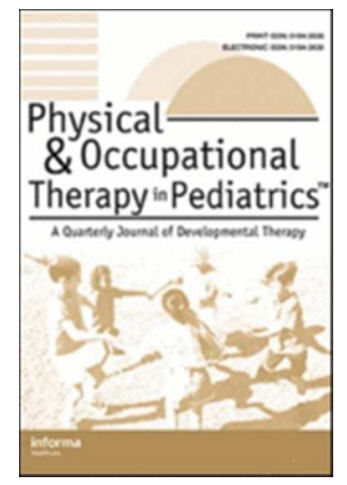

\title{
Development, Implementation, and Evaluation of the Apollo Model of Pediatric Rehabilitation Service Delivery
}

\begin{tabular}{|r|l|}
\hline Journal: & Physical \& Occupational Therapy In Pediatrics \\
\hline Manuscript ID: & WPOP-2012-0018.R2 \\
\hline Manuscript Type: & Original research \\
\hline Keywords: & $\begin{array}{l}\text { service delivery, health systems }<\text { Themes, knowledge translation, } \\
\text { evidence-based practice < Themes, quality of life < Themes }\end{array}$ \\
\hline \multicolumn{2}{|l}{} \\
\hline
\end{tabular}

SCHOLARONE ${ }^{\text {m }}$

Manuscripts 
KEYWORDS. Rehabilitation, pediatric, children; service delivery model, service organization, quality of care, program evaluation. 
The Canadian public rehabilitation systems are under pressure; the increasing identification of childhood disability is not matched by available resources, creating waiting times, service challenges and concerns about unmet needs (Ehrmann Feldman et al., 2005; Feldman, Swaine, Gosselin, Meshefedjian \& Grilli, 2008; Grilli et al., 2007; King, Cathers, King \& Rosenbaum, 2001; Miller et al., 2008). Any reorganization of services is thus seen as pitting service accessibility against service quality. We believe creative solutions exist to address both aims simultaneously through the implementation of evidence-based service delivery model. However, so far, the few documented service delivery models are unlikely to help clinicians and administrators structure their services to take into account service accessibility and quality.

This article presents Apollo, a new pediatric rehabilitation service delivery model. A historical perspective on the planning, implementation and evaluation phases of the process is described. During these times of accountability, and because many rehabilitation programs around the world face similar challenges, we hope the lessons we learnt will help others make informed decisions when reorganizing their services.

The program under study is one of six rehabilitations programs of the Estrie Rehabilitation Center located in Québec, Canada. Each year, the Program provides out-patient services to approximately 1000 families of area resident children aged 0-18 years. Children with different diagnoses are treated within five sub programs: 1) developmental delay (e.g. Down syndrome); 2) dyspraxia (e.g. developmental coordination disorders); 3) motor (e.g. cerebral palsy); 4) speech and language (e.g. language disorders); 5) teenagers (youth with mixed diagnoses attending high school). Before the service reorganization, an interdisciplinary rehabilitation team provided services mainly on an individual basis, either in the rehabilitation center or at one of the seven rural sites or in the child's community (e.g. school). Interventions were provided based on the Center's philosophy including the Disability Creation Process (Fougeyrollas, Cloutier, Bergeron, 
Côté \& St-Michel, 1998), similar to the international classification of functioning (Levasseurs, Desrosiers \& Tribble, 2007), ecosystem approaches (Bronfenbrenner \& Crouter, 1983), partnership theories (Bouchard, Talbot, Perlchat \& Boudreault, 1998) and the philosophy of human caring (Frampton, Gilpin \& Charmel, 2003), having principles similar to those of familycentered care (Rosenbaum, King, Law, King \& Evans, 1998).

Each year, due to limited resources, the names of many children were added to a waiting list. In March 2007, 448 children were waiting for services, for some as long as three years, depending on different factors including the urgency of their needs. Since 2002, the Program has explored ways to reduce waiting times, such as offering a one-time interdisciplinary evaluation including recommendations (e.g. home exercise program) to families having a child on the waiting list. Despite such efforts, in 2005 , accessibility remained an issue so the managers of the Program and the Center's director presented a proposal to the Québec Health and Social Services Ministry to develop and evaluate a new model of pediatric rehabilitation services.

The new service delivery model was called Apollo after the movie Apollo 13 where the crew of the space shuttle had to figure out a way to use what they had onboard to create a new $\mathrm{CO}_{2}$ filter to return to earth. In our case, the Program team was faced with the dilemma of reducing waiting time, using existing resources while ensuring quality services. The Program managers believed the following changes were required: 1) revision of admission procedures and mechanisms for evaluation and service orientation; 2) development of structured community interventions; 3) development of an annual calendar of recurring group activities; 4) development of criteria and guidelines for individual therapies.

To further develop the Apollo model and evaluate the service reorganization, the Centre's leaders initiated a participatory action research (PAR) project. The first author, a physiotherapist and research coordinator of the Center familiar developed the PAR. Various types of PAR exist 
(Tandon, 2002; Weaver \& Cousins, 2007), but in our case, PAR was used as a practical strategy to solve problems: participants' empowerment can occur during the research process, but the primary goal was to solve practical problems and provide organizational support. Indeed, PAR is reported to foster changes in professional practices and to facilitate the implementation of new service delivery models in health and rehabilitation (Glasson et al., 2006; Hills, Mullett \& Carroll, 2007; Suarez-Balcazar, Martinez \& Casas-Byots, 2005).

At the end of 2005, the Program received funding and the clinical and the research projects started. Figure 1 illustrates the projected phases, the real timeline and the main activities of each phase. In reality, the phases overlapped; the implementation phase was initially planned to last a year but took two years, the evaluation phase ran throughout the whole project and, even once the project was over, the program continued implementing aspects of the Apollo model.

[Insert figure 1 about here]

\section{PLANNING PHASE}

\section{Working Committee}

Involving stakeholders is reported as a useful strategy to facilitate the success of a quality improvement project (Tandon, 2002). Initial consultations about the changes to the program were conducted with family-, community partner-, and clinician representatives and administrators. The decision was made to combine the two latter groups to create a working committee with the mandate to further develop the model and oversee its implementation and evaluation. Members of this committee would also be in charge of consultations with family and community partner representatives, and of keeping them informed throughout the project. This committee was composed of the head of the Program, the three clinical coordinators, a research coordinator, an organizational development counselor and five clinician representatives delegated by their colleagues (i.e. a physiotherapist, an occupational therapist, a speech and language therapist, a 
special educator and a social worker). Members met about 3 hours weekly over the planning period to develop the model based on the data collected and the literature review.

\section{Describing current practices}

Before initiating any changes in a program, conducting an organizational diagnostic helps identify its current strengths, weaknesses, opportunities and threats (SWOT) (Pollack, 1994). In April 2006, all clinicians of the Program were thus invited to complete a SWOT questionnaire. Results identified that clinicians perceived services to be of good quality, highly individualized and family-centered, but service accessibility and psychosocial support needed improvement (SWOT results can be found in Camden, Swaine, Tétreault \& Bergeron, 2009).

At the same time, group discussions about children's needs and potential services were held separately with four groups of administrators and representatives of the service providers, families and community partners. A comprehensive list of needs $(n=67)$, classified according to the DCP (e.g. deficits, capabilities, environmental factors, life habits) (Fougeyrollas et al., 1998) was generated. Subsequent services $(n=88)$ deemed essential to meet these needs were grouped according to different intervention categories. Interestingly, Program managers and clinician representatives identified more needs and services relating to individual and group interventions, whereas community partners and parents reported more needs and services related to service orientation and follow up, and community interventions, focusing more on social participation (unpublished results). For instance, community parents and parents wanted more information and tools to foster communication and service planning among stakeholders in a child's different environments, and more interventions to target function and daily life activities, such as doing homework.

Based on the group consultations and the SWOT results, the goal of the reorganization process shifted from addressing waiting times, but to include service quality. Service quality was 
defined by the working committee team as services that are accessible (i.e. reduced waiting times in our case) and foster well being and social participation. With these service reorganization goals in mind, the working committee members started examining the literature for a service delivery model that could further help develop the Apollo model.

\section{Models and Evidence to Guide the Service Reorganization Process}

Applied models of service delivery help rehabilitation centers structure their services. These models should be interdisciplinary and specify the type of services required to cover the broad scope of children's needs across their lifespan (King et al., 2002). However, few models of rehabilitation service delivery are published; papers relate only to one health profession or to general models offering limited guidelines for service organization in pediatric rehabilitation. Others propose strategies (e.g. 30 minute sessions rather than 60 minutes, changes in administrative procedures and increased group interventions) to reduce waiting times for children with disabilities (Clow et al., 2002; Miller et al., 2008), but these are more punctual solutions rather than global service reorganization strategies.

In 2006-2007, the Life Needs Model (LNM) (King et al., 2002) was the only model found offering guidance to reorganize the Program's services, its underlying values fitting well with the center's philosophy of care. The LNM is a developmental, social-ecological, community and transdisciplinary model of pediatric rehabilitation services delivery based on holistic needs of children, their family and the community (King et al., 2002). These needs are grouped into three different spheres of life: the personal (e.g. self-esteem and abilities), the interpersonal (e.g. relationships with others), and the external (e.g. roles with regards to societal life) spheres. For each sphere, short-term objectives are identified to foster children's social participation (see Table 2 or King et al., 2002 for additional details). 
The LNM is "an applied model that combines a focus on structure (services structured to meet needs), process (family-centered service), and outcomes (participation and quality of life)" (King et al., 2002, pp. 59). Practical guidance for service organization is offered through six questions: Why services should be offered? Who should benefit from rehabilitation services? What kind of services should be offered? Where, When and How services should be delivered? The desired 'who', 'where', 'when' and 'how' of the Apollo model were similar to those of the LNM (see Table 1).

\section{[Insert Table 1]}

Regarding 'why' services should be offered, both models shared the same common long term goal of social participation, but the Apollo model also was aimed at reducing waiting times. Moreover, we felt that the LNM had a strong focus on processes and outcomes, but offered little guidance on how to structure and coordinate rehabilitation activities. The LNM did not sufficiently describe 'what' services are required. More concrete examples of services required to meet children's needs (e.g. groups offered in the community) are provided in King, Tucker, Baldwin \& LaPorta (2006), but these authors did not explain how to integrate all the different service components into a global, coordinated program. More recently, the Relational-Goal model was published to help programs structure their services (King, 2009), but it too offers little guidance with regards to service coordination and increasing service accessibility.

\section{The Apollo Model}

The Apollo model, which ended up looking like a space shuttle, is illustrated in Figure 2. The working committee developed the Apollo model from three sources of information: 1) the changes and the diversity of types of services identified by the Program managers at the beginning of the project, 2) the strengths of the LNM, such as the consideration of children's developmental issues, and 3) the inclusion of strategies to foster service coordination and to 
ensure the program's efficiency and service accessibility. In June 2007, the working committee created the final version of the Apollo model which included service accessibility mechanisms, while considering children's lifespan, life transitions, children age's groups and important community partners related to a specific child's age. The arrow shape suggests the model should focus on long term outcomes involving multiple and coordinated interventions within a continuum of care.

[Insert Figure 2 about here]

The definitions, specific objectives, and service delivery components for each intervention category of the Apollo model and the links with the LNM is presented in Table 2. Although each service delivery component addresses different goals of service quality, the coordinated service delivery process and the follow-up process are perceived to contribute to continuous service accessibility throughout the rehabilitation process; the community, group and individual interventions are perceived to specifically aim at fostering social participation; and the adoption of human caring principles are thought to foster well being.

[Insert Table 2 about here]

Following the admission in the program, the 'first contact' was added as a new type of services, followed by the coordinated service delivery and follow-up. The first contact builds on the literature affirming that administrative procedures should be reviewed to decrease waiting times and that a quick contact with someone from a rehabilitation centre before treatment begins can help decrease family anxiety and address information and support needs (Miller et al., 2008). The process of coordinated service delivery and follow-up is proposed to integrate all the different service components into a global, coordinated program and supported by the notion that coordinated services influence program efficiency (King \& Meyer, 2006). The individual, group and community interventions originally included in the model were maintained; the former are 
the traditional way of providing rehabilitation services, but group and community interventions are increasingly reported as more cost-effectiveness methods of service delivery (Bayona, McDougall, Tucker, Nichols \& Mandich, 2006; Hung \& Pang, 2010).

The first contact is initiated once standard admission procedures and eligibility screening are completed. Once the standard eligibility/admissibility letter is sent to the family, a social worker calls the family to offer information about the upcoming services and support, and asks the family about their needs. If the social worker thinks the family may be at risk of a crisis, an individual therapy session is offered to them. Another form of first contact includes inviting parents to a family group meeting to provide them general information. This social worker becomes the family key worker, generally described as an individual responsible for providing information and emotional support to families, and being the liaison among different services (Rahi, Manaras, Tuomainen \& Hundt, 2004). In our case, the key worker was initially the social worker but later, any service provider involved with the family could assume such roles.

Coordinated service delivery and follow-up is initiated once the social worker has forwarded the information obtained during the first contact to the clinical coordinator assigned to the child. The clinical coordinator is a service provider whose role is to coordinate services for a group of children of similar age, diagnosis and living in the same area. The clinical coordinators work with key workers and interdisciplinary evaluation teams to identify children's needs. Rehabilitation care pathways developed by interdisciplinary rehabilitation teams within each of the subprograms, using clinical expertise and evidence from the literature, are used to plan services and ensure that family needs are addressed in a timely fashion.

Pathways were developed for each subgroup of children population (according to diagnosis and prognosis) and specify the type of services (e.g. group or individual interventions) children should receive and the timing of the interventions (e.g. at 3 or at 5 years old). Pathways are 
intended to be used in conjunction with intervention plans, where interdisciplinary teams, community partners and families meet to determine the services. During these meetings - and throughout the rehabilitation process - the key worker facilitates the relations between the family and the rehabilitation team to ensure that the information and family's psychosocial needs are met. A documentation center providing access to support and psychosocial resources for families is also being developed to respond to these needs.

Coordinated service delivery and follow-up allows for an ongoing coordination of the different services by fostering communication among rehabilitation team members (Figure 3). For instance, forms are completed by clinicians at the end of group intervention sessions and sent to clinical coordinators to ensure a global long-term vision of the children's needs and to further plan required services. These characteristics distinguish Apollo from other service delivery models where different types of services are also offered but only based on one clinician's judgment as opposed to a global service plan.

[Insert Figure 3 about here]

Community interventions target needs common to all children with disabilities through interventions designed for community partners as opposed to for an individual child. Services aim to respond to the needs of many children enrolled or not in the rehabilitation program. This contrasts with community-based group interventions that are center-lead with a focus for a defined group of children (e.g. Batorowicz, McDougall \& Sheperd, 2006). The Program felt that community interventions could help to develop a more inclusive community and, thereby, facilitate children's social participation. Moreover, we perceived working on the needs of community partners as more efficient than responding to one child's needs at a time. Collective files were developed where the «client» was a community partner (e.g. a school), These $\underline{\text { collectives files are used like the traditional files (i.e. to register goals, activities, hours of services }}$ 
provided to the client, etc.), but instead of targeting a child with disability, they target a community partner. As such, they record activities such as general training to increase teachers' $\underline{\text { skills in a school, instead of an intervention to increase one teacher's skills with regards to one }}$ particular child. Mechanisms of information exchange between service providers and the community partners and formal agreements about the roles of each group were also included in these collective files.

Group and individual interventions differ from community interventions as they target one or many children registered in the Program, whether the activity is conducted in the rehabilitation center or in the community. Objectives of these interventions not only target children, families, and community partner skills but also needs for support and information. Instead of identifying objectives exclusive to group or individual interventions, we felt the choice of service delivery component should depend on child and family needs and characteristics (e.g. needs for finetuning versus gross motor development, child's behavior with peers, family's place of residence, etc.). Criteria based on family needs and characteristics were developed to guide the choice of the best service delivery component, each one having different advantages. We perceived Group interventions as a way to increase a child's motivation in the rehabilitation process, foster peer modeling and the development of social skills. In contrast, we believe that individual interventions use a more personalized approach and allow service providers more time to concentrate their attention and expertise on an individual child.

\section{IMPLEMENTATION OF THE APOLLO MODEL}

Implementation consists of putting into operation a new intervention (Contandriopoulos, Champagne, Denis \& Avargues, 2000). In our case, The Apollo model began to be implemented in 2008. One might think this is straight forward, but there are many challenges to implementation. Literature exists with regards to the facilitators and barriers to the 
implementation of new interventions and changing professional practices (Damschroder et al., 2009). However, recommendations are often general and relate to the planning phase, providing few guidelines about how to address real-life challenges during the implementation of a new service delivery model in rehabilitation. In our case, high turnover of project leaders and the need to standardize practices across professionals within the same discipline were challenges to fully implementing the model (see Camden, Swaine, Tétreault \& Carrière, 2011 for more details on the change process). Here we briefly describe the implementation process of each of the service delivery components and share some lessons learnt.

The first contact was first piloted in a subprogram in one region before being implemented within the rest of the program. During the piloting, materials were developed (e.g. an interview guide and informational resources for parents) to support the new roles of the social workers. Moreover, the social worker for the subprogram was part of the working committee and understood the underlying philosophy of the new model and the first contact. She helped train other social workers. The first contact was reported as being very appreciated by parents, who reported decreased anxiety (unpublished data), and it helped decreased waiting times.

Challenges to implementation related principally to integration within the overall model (i.e. continuity within the process for coordinated service delivery and follow-up) and adaptation of the model to the specific characteristics of each subprogram. For instance, depending of the children's characteristics and the service organization within each subprogram, the Program team realized that an extensive data collection was not always necessary as it was originally planned. On the other hand, some subprogram interdisciplinary rehabilitation teams wanted the social workers to collect additional data (e.g. child's communication skills) to help refer the child to services. The first contact has evolved as the other service delivery components were implemented in each subprogram. 
The Coordinated service delivery and follow-up component has been the most challenging to implement. Indeed, it required major changes with regards to how services were coordinated. Before, each clinician was responsible for determining the services offered to a particular child. In the Apollo model, clinicians have to work together in teams to determine the services to offer and each one has to respond to some of the child's needs as opposed to all of them. This required more coordination among clinicians. The clinical coordinator was identified as the leader of this process, but many challenges were faced, including the clinician's perception of being constrained in their professional autonomy (e.g. resistance to being told to offer a particular type of services for a determined amount of time) and the lack of a proper database system to plan services for a particular child. The rehabilitation care pathways were challenging to implement; much time, effort and negotiations were required by the interdisciplinary teams to review them and to agree on the services to offer within each subprogram. Revisions are still ongoing in the different subprograms and strategies are being explored to foster optimal utilization. Each subprogram team also reviewed the role of the key worker and decided upon the criteria required to identify the clinician who would play this role.

Community interventions led to the creation of a partnership with a regional walking group to organize hikes for children with disabilities and another partnership with a massage therapist to support the development of adapted massages for newborns with physical disabilities. The collective files contributed to the structuring of the community interventions and to obtaining recognition for the hours clinicians worked within the community. This recognition was important since community interventions are misleading in that they show the Program's 'productivity' as being decreased because these services cannot be tagged to a specific child. The compilation of these files, although not formally recognized by the Québec Health Ministry, enabled documenting the time spent providing this service delivery component. 
Effectively integrating community interventions into the service delivery model was challenging, especially with regards to the time needed to develop agreements with community partners (more examples and explanations can be found in Camden et al., 2011a). Clearly identifying which activities required directors' agreements, and which ones did not, helped further develop community interventions, giving clinicians the ability to move forward and work directly with partners. Identifying a target percentage of work time dedicated to community interventions was also discussed as a strategy to foster the implementation of community interventions, but no clear guidelines have been identified yet.

Group interventions are the service delivery component that most dramatically increased during the implementation of the Apollo model $(n=20$ before compared with $n=47$ after implementation). Group interventions are perceived to be more efficient than individual interventions. Efficiency indeed increased over the years, as illustrated by the clients/clinician administrative indicator, which increased from 23.8 children per clinician to 32.1, from 2007 to 2009. During the same period, the cost per client decreased from $\$ 3,204.65$ to $\$ 2,585.22$, without any indicator suggesting a decrease in service quality. Although these data reflect the overall impact of the service reorganization, many stakeholders associated this increase in efficiency to group interventions. However, many organizational issues were identified with the increase utilization of group interventions, such as having the required resources (e.g. space and materials) and ensuring clinicians are adequately prepared to intervene in groups, with adequate administrative support (e.g. to send group invitations and to do the paperwork). Detailed results and stakeholders' perceptions about group interventions can be found elsewhere (Camden, Swaine \& Tétreault, 2011).

For the individual interventions, the challenge has not been implementation but rather to limit their use. Decreasing the amount of individual interventions was necessary to increase the use of 
other service delivery components. The criteria identified for choosing individual interventions were discussed among teams while reviewing the care pathways. Many negotiations are still undergoing within the subprograms to reach a consensus on when to use groups and individual interventions for particular needs, for specific groups of children.

\section{EVALUATION AND CONTINUOUS QUALITY IMPROVEMENT}

The evaluation is normally the final phase of a service reorganization project because it traditionally aims to document the outcomes. However, even for outcome evaluations, before beginning a reorganization process, it is essential to negotiate the evaluation questions and tools with the stakeholders to take into account their interests and needs to foster further use of the results (Patton \& LaBossière, 2009). Ideally, data collected should cover not only the outcomes, but also structure and the processes (by using implementation evaluation, for instance), as advocated by Donabedian (1966). Data collected should target different moments in the rehabilitation process, such as the first contact and referring, the evaluation, the intervention and the discharge phases (Eldar, 2000).

Despite of all the challenges encountered, the Program team succeeded in reorganizing its services and outcomes were identified during the evaluation phase. In our case, many discussions to identify stakeholders' information needs and the relevant tools were held in 2006 and over the course of the project. To evaluate the service reorganization outcomes and document the change process, we decided to: 1) use a SWOT questionnaire similar to the one used in 2006 and the Measure of Processes of Care (MPOC - King, Rosenbaum \& King, 1997) in 2007, 2008 and 2009; 2) conduct interviews and focus groups with families, clinicians and administrators in 2008 and 2009; and 3) develop an information system. First, the SWOT provided a clear portrait of the Program's situation overtime and results showed that after the implementation of the model, clinicians felt an increase in service accessibility but worried about the possibility of not being 
able to tailor services according to children's needs (Camden et al., 2011a). Families' and clinicians' perceptions of the service quality measured by the MPOC indicated that despite the upheavals caused by the reorganization of services, the quality was maintained during the three years (Camden, Swaine, Tétreault \& Brodeur, 2010).

With regards to the development of an information system, data available at the beginning of the reorganization process only allowed documenting some indicators, such as the waiting time for a first service. After various meetings of the working committee, the Program developed in 2008 a list of additional indicators related to the program's structure (e.g. ratio child/clinician), processes (e.g. number of groups) and outcomes (e.g. changes in the children's social participation). By the end of the reorganization process, more data were routinely collected (e.g. a standardized method of calculation determined the exact number of groups provided annually, the number of new groups created, the number of sessions of each group and the number of participating children).

We were unable to implement some indicators into routine program evaluation. For instance, the Life Habits (Fougeyrollas et al., 2001) was chosen to evaluate children's social participation but its implementation would have required training clinicians to use it in a standardized manner; due to busy caseloads, using quantitative tools to formally evaluate the impact of social participation was not given priority. Moreover, because the tool measures a broad range of life habits (each influenced by many life events), doubts were raised about the relevance of this information with regards to the overall program evaluation and its ability to support continuous quality improvement efforts.

We strongly recommend exploring ways to integrate a formal data collection process to evaluate the Program's impact on children's social participation. Continuous quality improvement, or the process of sustaining efforts to further improve the implementation of the 
Apollo model and the quality of the services, would ideally be built on data routinely collected in a standardized manner. A new provincial-information system should be implemented shortly allowing programs to collect more detailed data, and discussions are ongoing about which indicators best reflect a program's processes and outcomes. Although the Apollo service reorganization process is over, the project keeps influencing how decisions are made within the Program and has the potential to influence future directions province-wide.

\section{CONCLUSION}

Few service delivery models are available to guide the efforts of pediatric rehabilitation programs wishing to reorganize services. Even fewer descriptions of service reorganization processes are reported. Sharing experiences is needed for programs to learn from each other and to increase the effectiveness of rehabilitation service delivery. Although the Apollo Model was developed specifically for children with physical disabilities in Canada, we believe it could inspire others in different socio-political environments as it builds on universal principles that can easily be applied in different settings. For instance, the Apollo model shares similarities with early intervention models in the United States, where different types and intensity of services are promoted according to patients' needs (Ramey \& Ramey, 1998).

In our experience, the collaborative process is a great facilitator for reorganizing services. We strongly recommend that children, families, and community partners are included throughout the whole process. We planned to consult more frequently with these important stakeholders during the project, but time constraints made this difficult - for this reason, we recommend fostering participation of all stakeholder at the very beginning of any reorganization project. Knowing the vision of children, families, and community partners about what constitutes best services and 
how to achieve them combined with the integration of clinical experiences and research evidence, would help us broaden the vision of optimal service delivery.

The Apollo model is grounded in scientific evidence and preliminary data are promising. More work is needed to fully implement the Apollo model and to translate evidence to practice. This model provides the structure for organizing rehabilitation programs, but its service delivery components need to be constantly updated to stay aligned with the evidence. Further investigations are needed to better understand the individual contributions of each of the service delivery components and to compare the cost-effectiveness of this model with others.

\section{DECLARATION OF INTEREST}

The authors report no conflicts of interest. The authors alone are responsible for the content and writing of the paper. 


\section{REFERENCES}

Batorowicz, B., Mcdougall, S., \& Shepherd, T. (2006) AAC and community partnerships: The participation path to community inclusion. Augmentative and Alternative Communication, 22(3), 178-195.

Bayona, C. L., McDougall, J., Tucker, M. A., Nichols, M., \& Mandich, A. (2006) School-based occupational therapy for children with fine motor difficulties. Physical \& Occupational Therapy in Pediatrics, 26(3), 89-110.

Bouchard, J. M., Talbot, L., Perlchat, D., \& Boudreault, P. (1998) Partenariat entre les familles et les intervenants: qu'observe-t-on dans la pratique? In J.P. Pourtois (Ed.), Regards sur l'éducation familiale. Représentation-Responsabilité-Intervention (pp. 189-201). Bruxelles.

Bronfenbrenner, U., \& Crouter, A. C. (1983) The Evolution of Environmental Models in Developmental Research. In W. Kessen (Ed.), Handbook of Child Psychology: History, Theory, and Methods (4th Ed. ed.) (pp. 499-568). New York.

Contandriopoulos A-P, Champagne F, Denis J-L, Avargues M-C. (2000) L'évaluation dans le domaine de la santé : concepts et méthodes. Revue d'Epidémiologie et de Santé Publique, 48, 517-539. 
Camden, C., Swaine, B., \& Tétreault, S. (2011b) Increasing the use of group interventions in a pediatric rehabilitation program: Perceptions of administrators, therapists and parents. Physical and Occupational Therapy in Pediatrics, 2011, Early online: 1-16.

Camden, C., Swaine, B.R., Tétreault, S. \& Brodeur, MM. (2010) Reorganizing pediatric rehabilitation services to improve accessibility: Do we sacrifice quality? BMC Health Services Research, 10, 227.

Camden, C., Swaine, B., Tétreault, S. \& Carrière, M. (2011a) Going beyond the identification of change facilitators to effectively implement a new model of services: Lessons learned from a case example in pediatric rehabilitation. Developmental Neurorehabilitation, 2011, 14(4), 247-260.

Clow, D., Mustafa, A., Snollar, J., Wood, N., Reid, J., \& Sinden, S. (2002) Reducing waiting times associated with integrated child health service. The Journal of the Royal Society for the Promotion of Health, 122(4), 245-250.

Damschroder, L., Aron, D., Keith, R., Kirsh, S., Alexander, J., \& Lowery, J. (2009) Fostering implementation of health services research findings into practice: A consolidated framework for advancing implementation science. Implementation Science, 4(1), 50.

Donabedian A. (1966) Evaluating the quality of medical care. Milbank Memorial Fund Quarterly, 44, 166-206.

Ehrmann Feldman, D., Couture, M., Grilli, L., Simard, M. N., Azoulay, L., \& Gosselin, J. (2005) When and by whom is concern first expressed for children with neuromotor problems? Archives of Pediatrics \& Adolescent Medicine, 159(9), 882-886.

Eldar, R. (2000) A conceptual proposal for the study of the quality of rehabilitation care. Disability \& Rehabilitation, 22(4), 163-169. 
Feldman, D. E., Swaine, B., Gosselin, J., Meshefedjian, G., \& Grilli, L. (2008) Is waiting for rehabilitation services associated with changes in function and quality of life in children with physical disabilities? Physical \& Occupational Therapy in Pediatrics, 28(4), 291-304

Fougeyrollas, P., Cloutier, R., Bergeron, H., Côté, J., \& St-Michel, G. (1998) Classification québécoise : Processus de production du handicap. Lac St-Charles, QC: Réseau international du processus de production du handicap/ Société canadienne pour la Classification internationale des déficiences, incapacités et des handicaps (RIPPH/SCCIDIH).

Fougeyrollas, P., Noreau, L., Lepage, C., Boissière, L., Picard, R. \& St Michel, G. (2001) La mesure des habitudes de vie. Québec, QC: RIPPH.

Frampton, S., Gilpin, L., \& Charmel, P. (2003) Putting Patients First. San Francisco, CA: Jossey-bass.

Glasson, J., Chang, E., Chenoweth, L., Hancock, K., Hall, T., Hill-Murray, F., \& Collier, L. (2006) Evaluation of a model of nursing care for older patients using participatory action research in an acute medical ward. Journal of Clinical Nursing, 15(5), 588-598.

Grilli, L., Feldman, D. E., Swaine, B., Gosselin, J., Champagne, F., \& Pineault, R. (2007) Wait times for paediatric rehabilitation. Healthcare Policy, 2(3), e171-187.

Hills, M., Mullett, J., \& Carroll, S. (2007) Community-based participatory action research: transforming multidisciplinary practice in primary health care. Panamerican Journal of Public Health, 21, 125-135.

Hung, W. W. Y., \& Pang, M. Y. C. (2010) Effects of group-based versus individual-based exercise training on motor performance in children with developmental coordination disorder: A randomized controlled pilot study. Journal of Rehabilitation Medicine, 42, 122-128

King, G. (2009) A relational goal-oriented model of optimal service delivery to children and families. Physical \& Occupational Therapy in Pediatrics, 29(4), 384-408. 
King, G., Cathers, T., King, S., \& Rosenbaum, P. (2001) Major Elements of Parents Satisfaction and Dissatisfaction With Pediatric Rehabilitation Services. Children s Health Care, 30(2), $111-134$

King, G. \& Meyer, K. (2006) Service integration and co-ordination: A framework of approaches for the delivery of co-ordinated care to children with disabilities and their families. Child: Care, Health \& Development, 32(4), 477-492.

King, G., Rosenbaum, P. L., \& King, S. M. (1997) Evaluating family-centred service using a measure of parents' perceptions. Child: Care, Health \& Development, 23(1), 47-62.

King, G., Tucker, M. A., Baldwin, P., Lowry, K., LaPorta, J., \& Martens, L. (2002) A life needs model of pediatric service delivery: Services to support community participation and quality of life for children and youth with disabilities. Physical \& Occupational Therapy in Pediatrics, 22(2), 53-77.

Levasseurs, M., Desrosiers, J. \& Tribble, D. (2007) Comparing the Disability Creation Process and International Classification of Functioning, Disability and Health Models. Canadian Journal of Occupational Therapy, 74(2), 233-242.

Miller, A. R., Armstrong, R. W., Mâsse, L. C., Klassen, A. F., Shen, J., \& O’Donnell, M. E. (2008) Waiting for child developmental and rehabilitation services: an overview of issues and needs. Developmental Medicine \& Child Neurology, 50(11), 815-821.

Patton, M. Q., \& LaBossière, F. (2009). L'évaluation axée sur l'utilisation. Dans V. Ridde and C. Dagenais. Approches et pratiques de l'évaluation de programme. Montréal, QC: Presses de l'Université de Montréal.

Pollack $_{2}$ C._D. (1994) Planning for success: the first steps in new program development. Journal of School Nursing, 10(3), 11-15.

Rahi, J. S., Manaras, I., Tuomainen, H. \& Hundt, G.L. (2004). Meeting the needs of parents 
around the time of diagnosis of disability among their children: evaluation of a novel

program for information, support, and liaison by key workers. Pediatrics, 114(4), e477-482.

Ramey, C. T. \& Ramey, S. L. (1998). Early Intervention and Early Experience, American

Psychologist, 53(2), 109-120.

Rosenbaum, P., King, S., Law, M., King, G., \& Evans, J. (1998). Family-centred services: A concepual framework and research review. Physical \& Occupational Therapy in Pediatrics, $18(1), 1-20$.

Suarez-Balcazar, Y., Martinez, L. I., \& Casas-Byots, C. (2005). A participatory action research approach for identifying health service needs of Hispanic immigrants: Implications for occupational therapy. Occupational Therapy in Health Care, 19(1-2), 145-163.

Tandon, R. (2002). Participatory research: main concepts and issues. Dans R. Tandon, Participatory research: Revisiting the roots. New Delhi, India: Mosaic Books.

Weaver, L., \& Cousins, J. B. (2007). Unpacking the Participatory Process. Journal of MultiDisciplinary Evaluation, 1, 19-40. 
Projected phases

(

Main activities
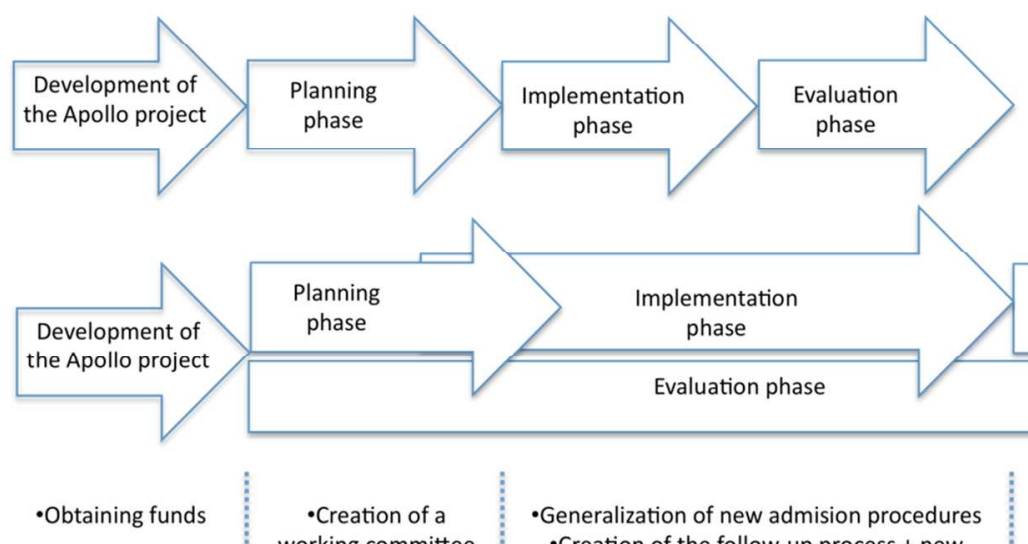

$$
\begin{gathered}
\text { Creation of a } \\
\text { working committee } \\
\text {-Data collection and } \\
\text { analysis } \\
\text {-Litterature review } \\
\text {-Development of the } \\
\text { new model } \\
\text {-Piloting of new } \\
\text { admission procedures }
\end{gathered}
$$

-Generalization of new admision procedures - Creation of the follow-up process + new coordination mechanisms -Increase number of groups -Development of community interventions - Standardization of individual interventions - Development of clinical and administrative tools to support the implementation of the different service delivery components -Data collection and analysis
0

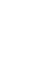

-Revision of the service delivery components (new groups, com

$$
\text { inter) }
$$

-Adaptation to

each subprogram

-Revision of the coordination •New organization in subprograms 


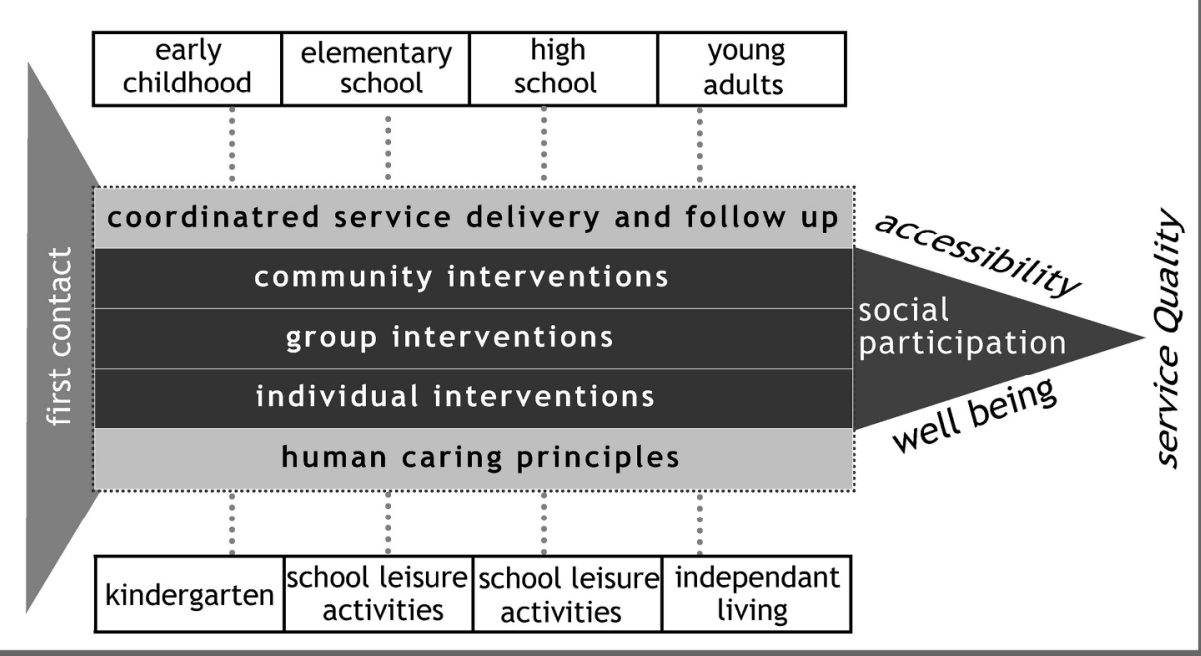

FIGURE 2. Final working version of the Apollo Model. $185 \times 235 \mathrm{~mm}(300 \times 300$ DPI $)$ 


\section{Follow up \\ (continuous coordination of service delivery through the child's life)}

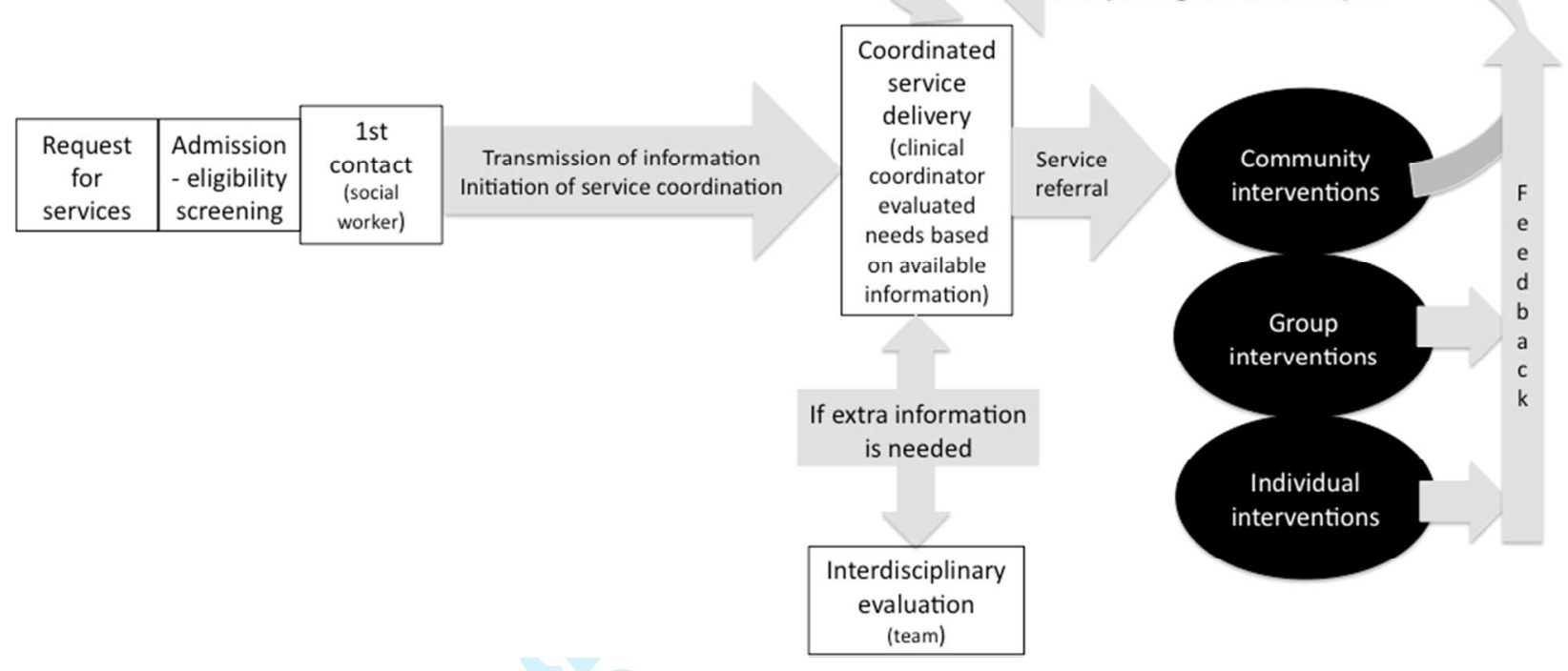




\section{Legends for FIGURES}

FIGURE 1. Timeline of the reorganization of services.

FIGURE 2. The Apollo Model.

FIGURE 3. Coordinated service delivery and follow-up. 
TABLE 1. Comparison of the Life Needs Mode1 and the Apollo Model.

\begin{tabular}{lll}
\hline Questions & Life Needs Model & Apollo Model \\
\hline 'Why?' & Supports children's participation in all areas of life. & $\begin{array}{l}\text { Offers quality services. Ensures accessibility to } \\
\text { services, fosters social participation for children and } \\
\text { families' well being. }\end{array}$ \\
\hline 'Who?' & $\begin{array}{l}\text { Major types of needs of children, family and } \\
\text { community members are specified. }\end{array}$ & $\begin{array}{l}\text { Services can target children, family and community } \\
\text { members. }\end{array}$ \\
\hline 'Where?' & Community based (services in the community). & $\begin{array}{l}\text { Services can be offered in different settings, including } \\
\text { in the community. }\end{array}$ \\
\hline 'When?' & Model focuses on key transitions in children's lives. & $\begin{array}{l}\text { Key transitions are included in the model and certain } \\
\text { services have higher priority according to child's age. }\end{array}$ \\
\hline 'What?' & $\begin{array}{l}\text { Family-centered approach should guide service } \\
\text { delivery. }\end{array}$ & $\begin{array}{l}\text { Human caring philosophy should guide service delivery. } \\
\text { Structured to meet children's age-specific needs. }\end{array}$ \\
& $\begin{array}{l}\text { Services can be delivered through individual, group } \\
\text { and community interventions. Some needs could } \\
\text { be addressed through the first contact and follow } \\
\text { up process. }\end{array}$ \\
\hline
\end{tabular}


TABLE 2. Specific objectives, links with the Life Needs Model and service delivery components within each intervention category of the Apollo model.

\begin{tabular}{|c|c|c|c|}
\hline Intervention category & Specific objectives & Links with the LNM & Example of service delivery components \\
\hline $\begin{array}{l}\text { First contact: } \\
\text { Mechanisms to foster a } \\
\text { first personalized contact } \\
\text { with the child's family } \\
\text { soon after program } \\
\text { eligibility }\end{array}$ & $\begin{array}{l}\text { Provide timely access to a first } \\
\text { rehabilitation service; } \\
\text { Answer questions and provide } \\
\text { information; } \\
\text { Identify needs for psychosocial } \\
\text { support. }\end{array}$ & $\begin{array}{l}\text { Services addressing family } \\
\text { members' needs for support } \\
\text { and } \\
\text { (interpersonal sphere). }\end{array}$ & $\begin{array}{l}\text { Phone call from social worker following reference; } \\
\text { Individual psychosocial therapy if required (e.g. social crisis); } \\
\text { Group information meetings for parents; } \\
\text { Forms to collect information on family needs; } \\
\text { Resources for specific (e.g. for the child) and general (e.g. tax } \\
\text { reimbursements) information to families; } \\
\text { Mechanism for information transfer to the interdisciplinary team. }\end{array}$ \\
\hline $\begin{array}{l}\text { Service coordination and } \\
\text { follow up: Follow up } \\
\text { refers to a group of } \\
\text { activities facilitating } \\
\text { access, coordination of } \\
\text { services and children's } \\
\text { and families' } \\
\text { participation in a } \\
\text { rehabilitation program. }\end{array}$ & $\begin{array}{l}\text { Assure access and continuity of } \\
\text { services according to needs; } \\
\text { Coordinate services to address all } \\
\text { needs; } \\
\text { Assure psychosocial support to } \\
\text { children and their family during the } \\
\text { rehabilitation process; } \\
\text { Facilitate access to general and } \\
\text { specific information. }\end{array}$ & $\begin{array}{l}\text { Services addressing family } \\
\text { members' needs for support } \\
\text { and information } \\
\text { (interpersonal sphere). } \\
\text { No specific component of the } \\
\text { LNM. }\end{array}$ & $\begin{array}{l}\text { Clinical coordinators responsible for long term service planning; } \\
\text { Service coordination process; } \\
\text { Mechanisms ensuring information exchange (e.g. forms and } \\
\text { procedures); } \\
\text { Interdisciplinary evaluation team proving recommendations to } \\
\text { families; } \\
\text { Key worker assigned to each family; } \\
\text { Information center. }\end{array}$ \\
\hline $\begin{array}{l}\text { Community interventions: } \\
\text { Interventions designated } \\
\text { to groups of people in the } \\
\text { community (e.g. school) } \\
\text { without targeting a } \\
\text { specific child in the } \\
\text { program. }\end{array}$ & $\begin{array}{l}\text { Facilitate community openness to } \\
\text { social integration; } \\
\text { Increase physical accessibility and } \\
\text { diminish barriers; } \\
\text { Encourage and facilitate the } \\
\text { emergence of programs and services } \\
\text { led by the community; } \\
\text { Facilitate, influence and support social } \\
\text { policy having a positive impact on } \\
\text { people with disabilities; } \\
\text { Facilitate community partners' skill } \\
\text { development. }\end{array}$ & $\begin{array}{l}\text { Services addressing } \\
\text { community members' needs } \\
\text { for information and } \\
\text { education (external sphere) }\end{array}$ & $\begin{array}{l}\text { Training offered to community partners; } \\
\text { Information and resources for community partners; } \\
\text { Service providers' participation on different Boards (e.g. parents } \\
\text { association); } \\
\text { Counselling and support to community groups to develop inclusive } \\
\text { activities; } \\
\text { Development of collective files. }\end{array}$ \\
\hline $\begin{array}{l}\text { Group interventions: } \\
\text { Activities targeting } 2 \text { or } \\
\text { more registered clients. }\end{array}$ & $\begin{array}{l}\text { Maintain the integrity of organic } \\
\text { systems; } \\
\text { Develop capacities and compensatory } \\
\text { strategies; } \\
\text { Foster an adequate physical } \\
\text { environment; }\end{array}$ & $\begin{array}{l}\text { Services addressing mainly } \\
\text { children's foundational skills } \\
\text { (personal sphere) and applied } \\
\text { skill sets and needs for } \\
\text { support and information } \\
\text { (interpersonal sphere). }\end{array}$ & $\begin{array}{l}\text { Different group interventions available within an annual calendar } \\
\text { (e.g. developing children's preschool skills, parent groups to foster } \\
\text { communication abilities with their child, etc.); } \\
\text { Identification of the most important groups within the health care } \\
\text { pathways; } \\
\text { Groups can involve one or more discipline, with or without }\end{array}$ \\
\hline
\end{tabular}




\begin{tabular}{|c|c|c|c|}
\hline & $\begin{array}{l}\text { Promote the performance of life } \\
\text { habits; } \\
\text { Develop competencies of children and } \\
\text { their families; } \\
\text { Contribute to the social support and } \\
\text { well being of children and their } \\
\text { families. }\end{array}$ & $\begin{array}{l}\text { Services can also address } \\
\text { family (interpersonal sphere) } \\
\text { and community (external } \\
\text { sphere) needs. }\end{array}$ & $\begin{array}{l}\text { community partners; } \\
\text { Groups can be offered at the Center or in a community setting; } \\
\text { Groups can target children, their family or community partners; } \\
\text { Procedures for group development, children's referral and follow up. }\end{array}$ \\
\hline $\begin{array}{l}\text { Individual interventions: } \\
\text { Activities targeting } 1 \\
\text { registered client. }\end{array}$ & Same as for group interventions & $\begin{array}{l}\text { Same as for group } \\
\text { interventions }\end{array}$ & $\begin{array}{l}\text { Therapies can involve one or more discipline, with or without } \\
\text { community partners; } \\
\text { Therapies can be offered at the Center or in a community setting; } \\
\text { Therapies can target children, their family or community partners; } \\
\text { Identification of criteria for follow up and disclosure within the } \\
\text { health care pathways; } \\
\text { Utilization of priority codes for service providers' case-load } \\
\text { management. }\end{array}$ \\
\hline
\end{tabular}

